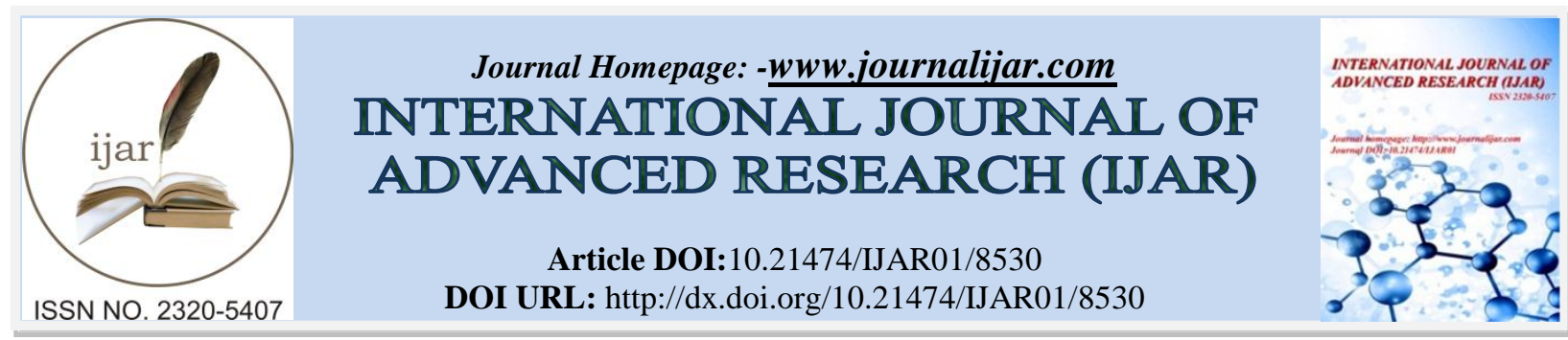

RESEARCH ARTICLE

\title{
STUDY OF SERUM ADIPONECTIN, LEPTIN AND CHEMERIN LEVELS INPATIENTS WITH TYPE 2 DIABETES MELLITUS AND OBESITY.
}

1. KPC Medical College \& Hospital, Kolkata.

2. Institute of Post-Graduate Medical Education and Research, A.J.C. Bose Road, Kolkata-700020, West Bengal, India.

\section{Manuscript Info}

\section{Manuscript History}

Received: 06 December 2018

Final Accepted: 08 January 2019

Published: February 2019

Key words:-

Adiponectin, Leptin, Chemerin, Type 2

Diabetes Mellitus And Obesity.

\section{Abstract}

This cross sectional study was done in the Department of Biochemistry, K.P.C. Medical College, Jadvapur, Kolkata. A total of 200 male patients of more than 18 years were studied. 200 patients were divided into Case and Control group depending on presence of diabetes mellitus. Each group consist of 100 patients.

In the present research, we showed that adiponectin was significantly higher in non diabetic control group with $\mathrm{p}<0.001$. In diabetic patients, adiponectin was suppose to be lower than normal. Statistically significant alliance was demonstrated in between Chemerin and Diabetes $(\mathrm{p}<0.001)$. Chemerin values were raised in diabetic individuals. Here, chemerin had statistically significant positive correlation with Cholesterol and triglycerides where $p<0.001 \&$ $p=0.003$ respectively. Similiarly, Lipoproteins like HDL, LDL and VLDL too had positive correlation with chemerin but of no statistical significance where $\mathrm{p}=0.585, \mathrm{p}=0.253, \mathrm{p}=0.147$ respectively. Glycemic parameters like FBS, PPBS and HbA1c were found to be positively correlated to chemerin with pronounced statistical significance ( $\mathrm{p}<0.001$ for each). Similar to Leptin, it was observed that chemerin too had positive correlation of statistical significance with HOMA -IR $(\mathrm{p}<0.001)$.

This study concluded that there is a strong association of each of the parameters, namely serum adiponectin, leptin and chemerin with diabetes as well as obesity.

Copy Right, IJAR, 2019,. All rights reserved.

\section{Introduction:-}

Type2 DM comprises about $90 \%$ of diabetic population of any country. Diabetes is fast gaining the status of a potential epidemic in India with more than 62 million diabetic individuals currently diagnosed with the disease ${ }^{1,2}$.

Insulin resistance, which implies impairment of insulin signaling in the target tissues, is a common cause of type 2 diabetes. Adipose tissue plays an important role in insulin resistance through the secretion of adipose-derived proteins, including tumor necrosis factor- $\alpha(\mathrm{TNF}-\alpha)$, plasminogen activator inhibitor-1, leptin, resistin, angiotensinogen and adiponectin. ${ }^{3,4}$ 
The growing prevalence of obesity has been reported as the leading cause of DM prevalence. Indeed, obesity, especially abdominal obesity, is a strong risk factor for cardiovascular disease (CVD) events and for insulin resistance that, usually, leads to T2DM. A hallmark of human aging is an increase of adipose mass, especially of visceral adipose mass, which is an independent risk factor for chronic heart failure in older people. The increase in hypertension, dyslipidemia, and impaired glucose metabolism, the known cluster factors for the metabolic syndrome, seems to be associated with the increasing prevalence of overweight and obesity in the elderly. Thus, obesity, insulin resistance, and aging appear to be closely linked.

Adiponectin is a protein hormone made of 244 aminoacids produced by the adipose tissue. It has pronounced effects on the metabolism of both carbohydrates and lipids in liver and muscle promoting uptake and oxidation of fatty acids by myocytes but blocks the synthesis of fatty acids and gluconeogenesis by hepatocytes ${ }^{5}$. It is considered to have anti-inflammatory and anti-atherogenic effects. Its serum concentration is inversely associated with adiposity. Levels are also low in presence of insulin resistance and show important relationships with development of type 2 Diabetes Mellitus and its complications.

Chemerin, amore recently identified adipose tissue specific adipokine, hasa crucial role in adipocyte differentiation and development,as well as in glucose and lipid metabolism . Raisedchemerin levels were found in obese subjects, in prediabeticstates, and in lean, overweight, and obese T2DM patients.

Leptin is an important adipose tissue-derived hormone that has been shown to be involved in pathways influencing the risk of cardiovascular disease and diabetes. ${ }^{6}$ Animal studies suggest that there is an inverse relationship between leptin levels and insulin secretion. ${ }^{7,8}$ Also, it has been suggested that the association between plasma leptin and diabetes may be a manifestation of an underlying leptin resistance mediated by obesity. ${ }^{9}$

However, relatively few studies have examined the putative association between leptin and diabetes, and their results have not been consistent. Some studies have reported that there is no association between plasma leptin levels and diabetes, ${ }^{10-12}$ whereas other studies have reported a significant positive association between plasma leptin levels and diabetes. ${ }^{13-16}$ However, two studies reported an inverse relation. ${ }^{17,}{ }^{18}$ Also, few studies reported that the association between plasma leptin and diabetes mellitus was observed only in men and not in women. ${ }^{15-17}$

Recently, chemerin (retinoic acid receptor responder 2, tazarotene-induced gene 2) was found highly expressed in adipose tissue. ${ }^{19,20}$ Chemerin is an agonist of the orphan G-protein coupledreceptor chemokine-like receptor 1 $(\text { CMKLR1, ChemR23) })^{21-23}$ that is expressed by cells of the innate immune ${ }^{20,22,24}$ system and,therefore, may further link obesity and inflammation. Chemerin issecreted as an inactive precursor, and activated through proteolytic cleavage by serine proteases of the coagulation, fibrinolytic andinflammatory cascades. Chemerin stimulates chemotaxis of thesecells indicating a function of chemerin and its receptor in theinnate immune response. ${ }^{22}$ Chemerin plays a vital role in adipocyte differentiationand development, and it may act as a modulator of differentmetabolic pathways in mature adipocyte ${ }^{25,26}$ namely, in the expression of adipocyte genes involved in glucoseand lipid homeostasis ${ }^{26}$ Moreover, chemerin associates with several metabolic syndrome markers, such as BMI,triglycerides, blood pressure, and insulin resistance. ${ }^{27}$ It was reported recently that insulin resistance seems to be apredictor of chemerin levels, independent of BMI .

Hence this study is conducted to estimate the levels of serum adiponectin, leptin and chemerin and predict the relation to type 2 Diabetes Mellitus and obesity.

\section{Materials And Methods:-}

Study area:-

Hospital based (K.P.C. Medical College \& Hospital, Jadavpur, Kolkata.)

\section{Study design:-}

Cross-sectional, descriptive and observational study in Type-2 diabetic individuals with/without family history of diabetes and with or without co-existence of hypertension(HTN).

\section{Sample size:-}

Case: 100 adult male patients of type-2 diabetes irrespective of, gender, nutritional status, socio-economic status , duration of diabetes . 
Further case will be divided into 2 subgroups

1. Diabetic and obese

2. Diabetic and non-obese

Control: 100 age and gender matched non diabetic male patient Further control will be divided into 2 subgroups

1. Non diabetic and obese

2. Non diabetic and non-obese

\section{Inclusion area:-}

All male patients with type 2 Diabetes Mellitus aged 30-70 years diagnosed according to American Diabetes Association criteria (FBS $\geq 126 \mathrm{mg} / \mathrm{dl}$ or 2 hour PPBS $\geq 200 \mathrm{mg} / \mathrm{dl}$ or HbA1c levels $>6.5 \%$ ).

Patients already on treatment for Diabetes Mellitus with Biguanides \& Suphonylureas will be categorized

\section{Exclusion area:-}

1. History of myocardial infarction and angina which are known to influence serum levels of adiponectin .

2. History of liver, kidney and thyroid diseases which are known to influence serum levels of adiponectin .

3. Gestational diabetes.

4. Patients on thiazolidinediones which are known to increase the levels of serum adiponectin.

5. Female patients were not include in the study.

\section{Data collection and interpretation:-}

The Study protocol, informed consent and case record form would be submitted to the Ethical Committee of K.P.C. Medical College \& Hospital for approval.

Informed consent will be taken from all participants before inclusion in the study in a language of their own understanding. Illiterate individual will give their finger-print (left-thumb impression) instead of signature.

After obtaining ethical clearance and permission from Head of the Departments of Medicine and Biochemistry and appropriate authority, data collection will be started by using pre-designed and pre-tested schedule, interviewing the participants, performing clinical examinations, laboratory investigations and record analysis. In this way all eligible subjects will be included in the study for a period of one year.

\section{Results:-}

We found that the mean value of adiponectin in case group was (3.61 \pm 2.16$)$ was less than control group (8.31 \pm 3.26$)$ with a significant correlation $(\mathrm{p}<0.001)$. From this result we can prove that adiponectin significantly decreased in diabetic patients.

We found that the mean leptin value in diabetic patients is $17.72 \pm 12.05$, and that of non diabetic control group is $13.78 \pm 10.30$. But the result is not statistically significant with $\mathrm{p}$ value 0.054 . We can prove that leptin level has no statistical significant relation with presence of diabetes.

It was found that the mean chemerin value in diabetic patients is $171.60 \pm 44.77$, and that of non diabetic control group is $96.64 \pm 23.46$. The result is statistically significant with $p$ value $<0.001$. From the above result we can prove that chemerin level has statistical significant relation with presence of diabetes. It increases with the presence of diabetes.

We found that the lipid subfractions in all 200 subjects were analyzed, it was found that all components except HDL was significantly higher in obese patients as compared to those without obesity irrespective of $b$ presence of diabetes. The above result proves that there is a statistical significance between hyperlipidemia and development of obesity irrespective of presence of diabetes.

It was found that the mean value of FBS in obese patients group was $(143.23 \pm 55.38)$ more than non obese group (122.33 \pm 49.53$)$ with a significant correlation (P 0.008). The mean value of PPBS in obese pt group (198.34 \pm 86.31$)$ was significantly higher than non obese group $(163.15 \pm 80.85)$ with $\mathrm{P}=0.003$. The above result proves that there is a statistical significance between level of hyperglycemia and development of obesity. 
It was found that the mean value of $\mathrm{HbAlc}$ in obese patients group was $(7.77 \pm 2.19)$ more than non obese group $(6.95 \pm 2.18)$ with a significant correlation $(\mathrm{P}=0.012)$. The above result proves that there is a statistical significance between level of HbA1c and obesity.

We found that the mean value of HOMA IR in obese patients group was $(6.24 \pm 3.24)$ more than non obese group (4.8 \pm 3.61$)$ with a significant correlation $(\mathrm{P}=0.026)$. Fig 16 is the pictorial representation of the above table. The above result proves that there is a statistical significance between level of HOMA IR and development of obesity.

It was found that the mean value of adiponectin in obese patients group was $(3.26 \pm 2.50)$ less than non obese group (7.71 \pm 3.40$)$ with a significant correlation $(\mathrm{P}<0.001)$. The mean value of leptin in obese patients group was $(31.33 \pm 7.50)$ more than non obese group $(8.75 \pm 1.75)$ with a significant correlation $(\mathrm{P}<0.001)$. The mean value of chemerin in obese patients group was $(143.73 \pm 47.35)$ more than non obese group (129.80 \pm 53.28$)$ with a significant correlation $(\mathrm{P}=0.033)$. The above result proves that level of leptin and chemerin significantly increase with development of obesity whereas level of adiponectin significantly decreases with development of obesity.

We found that statistically significant positive correlation between leptin and cholesterol $(\mathrm{p}<0.001)$, LDL $(p<0.001)$, VLDL $(p<0.001)$, TG $(p<0.001)$, PPBG $(p=0.05)$, BMI $(p<0.001)$. HDL had negative correlation with leptin but that had no statistical significance $(\mathrm{p}=0.142)$. FbG, Hbalc and HOMA IR had non-significant positive correlation with leptin with $\mathrm{p}$ value of $0.191,0.233$ and 0.390 .

It was found that statistically significant positive correlation between chemerin and cholesterol $(\mathrm{p}=0.044)$, TG $(\mathrm{p}=0.003)$, FBG $(\mathrm{p}<0.001), \mathrm{TG}(\mathrm{p}<0.001)$, PPBG $(\mathrm{p}<0.001)$, Hba1c $(\mathrm{p}<0.001)$, HOMA IR $(\mathrm{P}<0.001)$. HDL, LDL, VLDL had positive correlation with chemerin but that had no statistical significance with $p$ value $0.585,0.253$, 0.147 respectively. BMI also had non-significant positive correlation with chemerin with $p$ value of 0.115 .

We found that statistically significant negetive correlation between leptin and adiponectin with $p$ value $<0.001$ and correlation coefficient -0.455 . That proves leptin level decreases with increase adiponectin level and vice versa.

It was found that relation of HOMA IR value with Hbalc. All 200 patients are subdivided into 3 groups depending on their Hba1c value. Now the mean HOMA IR was calculated for each group of patient. It showed statistical significance with $\mathrm{p}$ value $<0.001$.

\section{Discussion:-}

This comparative study was done in the department of Biochemistry, KPC medical college Jadavpur, Kolkata. In the present study, 100 patients having diabetes were studied. 100 age and sex matched controls were also studied. In the group having diabetes, patients were subcategorised depending on the presence of obesity. Similarly the control group was also subcategorized into 2 groups depending on presence of obesity. 41 patients among the case group were found to be obese. 21 among 100 non diabetic patients were obese.

In this study, all patients were of the age group $>18$ years. Only male patient were included in the study as sexual dimorphism in adipose tissue function is evident. As a result gender may act as a confounding factor while we are taking adipokines hormone into consideration.

\section{Adiponectin And Presence Of Diabetes:-}

This present research showed the mean value of adiponectin in case group was $(3.61 \pm 2.16)$ was less than control group ( $8.31 \pm 3.26)$ with a significant correlation $(\mathrm{p}<0.001)$. From this result we can prove that adiponectin significantly decreased in diabetic patients. This result was in accordance with previously published reports. Helen $\mathrm{C}$ Looker et al recruited 1069 people in whom glycemia and renal function had been measured. Serum adiponectin adjusted for age, sex and body mass index was lowest in those with type 2 Diabetes Mellitus and highest in those with lower normal glucose tolerance ${ }^{28}$.

\section{Leptin In Accordance To Diabetes:-}

In the present study, the mean leptin value in diabetic patients was $17.72 \pm 12.05$, and that of non diabetic control group was $13.78 \pm 10.30$. But the result was not statistically significant with $\mathrm{p}$ value 0.054 . From the above findings we can conclude that leptin level has no statistical significant relation with presence of diabetes. But different observations were made by other studies. M.Abdelgadir et al studied 104 type 2 Diabetes Mellitus patients (both 
men and women) and 75 control subjects and showed that leptin levels were lower in diabetics than in controls of similar age and body mass index ${ }^{29}$.

\section{Chemerin \& Presence Of Diabetes:-}

The present study revealed that the mean chemerin value in diabetic patients was $171.60 \pm 44.77$, and that of non diabetic control group was $96.64 \pm 23.46$. The result was statistically significant with p value $<0.001$. From the above observation, we can prove that chemerin level has statistical significant relation with presence of diabetes. It increases with the presence of diabetes. In a study done by Susana Coimbra et al adiponectin and leptin levels in elderly patients with T2DMseem to be closely linked to obesity and to length of the disease. In the older group of T2DM patients, circulating chemerin concentrations are increased and seem to be independent of the length of disease and BMI, suggesting that adipocyte dysfunction is enhanced with aging. ${ }^{30}$

\section{Hyperlipidaemia And Development Of Obesity:-}

Here, lipid subfractions in all 200 subjects were analysed, it was found that all component except HDL was significantly higher in obese patients as compared to those without obesity irrespective of presence of diabetes. The above result proves that there is a statistical significance between hyperlipidemia and development of obesity irrespective of presence of diabetes. Bhatti MS et al found in a study that All the parameters except serum HDL level showed significant increase in obese persons while HDL level was significantly decreased.

\section{Diabetes \& development of obesity:-}

Our study showed the mean value of FBS in obese patients group was $(143.23 \pm 55.38)$ more than non obese group (122.33 \pm 49.53$)$ with a significant correlation ( $P$ 0.008). The mean value of PPBS in obese patients group (198.34 \pm 86.31$)$ was significantly higher than non obese group $(163.15 \pm 80.85)$ with $\mathrm{P}=0.003$. The aforementioned findings conclude that there is a statistical significance between level of hyperglycemia and development of obesity. This study found the mean value of HbA1c in obese patients group was $(7.77 \pm 2.19)$ more than non obese group $(6.95 \pm 2.18)$ with a significant correlation $(\mathrm{P}=0.012)$. So, the above outcome proves that there is a statistical significance between level of HbA1c and obesity. Diabetes and obesity are chronic disorders that are on the rise worldwide. In a study done by Abdullah S Al-Goblan, Mohammed A Al-Alfi et all it has beeb found that Body mass index has a strong relationship to diabetes and insulin resistance. In an obese individual, the amount of NEFA, glycerol, hormones, cytokines, proinflammatory substances, and other substances that are involved in the development of insulin resistance are increased. Insulin resistance with impairment of $\beta$-cell function leads to the development of diabetes. Gaining weight in early life is associated with the development of type 1 diabetes. NEFA is a cornerstone in the development of insulin resistance and in the impairment of $\beta$-cell function. New approaches in managing and preventing diabetes in obese individuals must be studied and investigated based on these facts. ${ }^{31}$

\section{Insulin Resistance \& Obesity:-}

The present research revealed the mean value of HOMA IR in obese patients group was $(6.24 \pm 3.24)$ more than non obese group (4.8 \pm 3.61$)$ with a significant correlation( $\mathrm{P}=0.026)$. The prior mentioned observation proves that there is a statistical significance between level of HOMA IR and development of obesity. In a study by Deva Gundupalli, Gagandeep Nagi, Gustavo G Zarini thedata indicated that insulin resistance is negatively influenced by anthropometric measures of obesity and inflammation. Our study contradicts the previous studies done on this topic by other authors.

\section{Adiponectin, leptin \& chemerin in accordance to obesity:-}

This study showed the mean value of adiponectin in obese patients group was (3.26 \pm 2.50$)$ less in comparison to non obese group $(7.71 \pm 3.40)$ with a significant correlation $(\mathrm{P}<0.001)$. The mean value of leptin in obese patients group was $(31.33 \pm 7.50)$ more than non obese group $(8.75 \pm 1.75)$ with a significant correlation $(\mathrm{P}<0.001)$. The mean value of chemerin in obese patients group was $(143.73 \pm 47.35)$ more than non obese group (129.80 \pm 53.28$)$ with a significant correlation $(\mathrm{P}=0.033)$. The above results suggest that level of leptin and chemerin significantly increase with development of obesity whereas level of adiponectin significantly decreases with development of obesity. Similarly, in a study done by Staiger H, Tschritter O et al it was found that both adipocytokines are associated with central body fat distribution, and serum adiponectin concentrations are determined predominantly by the visceral fat compartment. ${ }^{32}$ 


\section{Adiponectin \& lipid profile:-}

In this research, statistically significant negative correlation was found between adiponectin and cholesterol $(p<0.001)$, LDL $(p<0.001)$, VLDL $(p<0.001)$, TG $(p<0.001)$, FBG $(p<0.001)$, PPBG $(p<0.001)$, Hba1c $(p<0.001)$, HOMA IR ( $<<0.001)$, BMI ( $<<0.001)$. Only HDL had no significant correlation with adiponectin $(\mathrm{p}=0.617)$. In a study performed by Mi-Jin Kim, Kwang-Ha Yooet al found that In the diabetic group, the fasting adiponectin concentrations were negatively correlated with BMI ( $\mathrm{r}=-0.453)$, hip circumference $(\mathrm{r}=-0.341)$, fasting glucose concentrations $(\mathrm{r}=-0.277)$ and HOMAIR $(\mathrm{r}=-0.233)$. In addition, they were positively correlated with systolic blood pressure $(\mathrm{r}=0.321)$ and HDL cholesterol $(\mathrm{r}=0.291)$. The systolic blood pressure and HDL-cholesterol were found to be independent variables, from a multiple logistic regression analysis, which influenced the adiponectin concentration. Compared with the non-diabetic group, the adiponectin concentrations were significantly lower in the diabetic group, with the exception of obese males. ${ }^{33}$ In another study conducted by Jessica Smith, Maha Al-Amri1 et al ${ }^{1,2}$ found that Indian men and women had higher leptin and lower adiponectin concentrations than Caucasian men and women, respectively. Leptin (positively) and adiponectin (negatively) correlated with anthropometric parameters and lipoproteins in all four groups. Adiponectin concentrations in men were predicted (30.2\%) by HDL$\mathrm{C}$, total cholesterol, hip circumference and BF\% while in women $41.2 \%$ of adiponectin concentration was predicted by the apoB/apoA1 ratio, WHR and age. ${ }^{34}$ The results of our studies are similar to this study except for HDL.

\section{Leptin \&Lipid profile:-}

This study showed statistical significance with positive correlation between leptin and cholesterol ( $\mathrm{p}<0.001)$, LDL $(\mathrm{p}<0.001)$, VLDL $(\mathrm{p}<0.001), \mathrm{TG}(\mathrm{p}<0.001)$, PPBG $(\mathrm{p}=0.05)$, BMI $(\mathrm{p}<0.001)$. HDL had negative correlation with leptin but that had no statistical significance $(\mathrm{p}=0.142)$. FbG, Hbalc and HOMA IR had non-significant positive correlation with leptin with $\mathrm{p}$ value of $0.191,0.233$ and 0.390 respectively. Results of our study were found to be partly similar to this study. Adiponectin concentrations in men were predicted (30.2\%) by HDL-C, total cholesterol, hip circumference and BF\% while in women $41.2 \%$ of adiponectin concentration was predicted by the apoB/apoA1 ratio, WHR and age. ${ }^{34}$ In a study done by Pavani Bandaru we found that higher plasma leptin levels were initially found to be associated with diabetes mellitus after adjusting for age, sex, race/ethnicity, education, smoking, alcohol intake, hypertension, serum cholesterol and C-reactive protein [odds ratio (OR), 3.79; confidence interval (CI), 2.05-7.00; $\mathrm{P}$ trend <0.0001). However, when we additionally adjusted for body mass index (BMI), the association between plasma leptin levels and diabetes mellitus disappeared in both men (OR, 1.07; CI, 0.59-1.94; P trend $1 / 40.5004)$ and women $(\mathrm{OR}, 0.86 ; \mathrm{CI}, 0.49-1.51 ; \mathrm{P}$ trend $1 / 40.2819){ }^{35}$

\section{Chemerin \& Lipid Profile:-}

In our research, we found statistically significant positive correlation between chemerin and cholesterol $(\mathrm{p}=0.044)$,

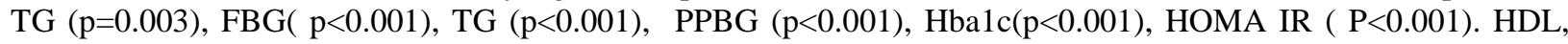
LDL, VLDL had positive correlation with chemerin but that had no statistical significance with $p$ value 0.585 , $0.253,0.147$ respectively. BMI also had non-significant positive correlation with chemerin with $\mathrm{p}$ value of 0.115 . Johanna Weigert, Markus Neumeier et al conducted a study. They found Circulating chemerin was similar in T2D and obese individuals but was significantly elevated in both cohorts compared to normal-weight individuals. These findings were partially matching to our results in respect to relation between chemerin and diabetes. Chemerin positively correlated with leptin, resistin and C-reactive protein (CRP). In T2D, chemerin was similar in male and female patients and increased in patients with elevated CRP. Chemerin was similar in PVS and SVS, indicating that visceral fat is not a major site of chemerin synthesis. Higher levels of chemerin in HVS demonstrate that chemerin is also released by the liver. Conclusions Visceral fat is not a major site of chemerin release, and elevated systemic levels of chemerin in obesity and T2D seem to be associated with inflammation rather than body mass index. ${ }^{36}$. The meta-analyses of MS and obesity markers done by Ya Li, Bingyin Shi, Sheli Li et al indicated that TG, TC, CRP BMI, TBF\%, WC, WHR and Leptin were positively correlated with chemerin, nevertheless, SBP, DBP, LDL-C,

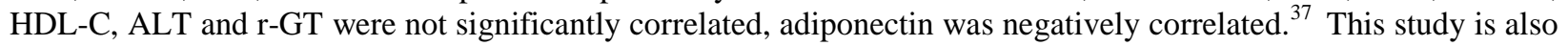
very much similar to our study except for BMI.

\section{Leptin \& Adiponectin:-}

Here, statistically significant negative correlation was observed between leptin and adiponectin with $\mathrm{p}$ value $<0.001$ and correlation coefficient -0.455 . This concludes leptin level decreases with increase adiponectin level and vice versa. No similar studies were found. 


\section{Insulin Resistance \& Hba1c:-}

In our study, we assessed the relation between HOMA IR value with Hba1c results. Total of 200 patients were subdivided into 3 group depending on their Hbalc value. On calculating the mean HOMA IR for each group of patient, we found statistical significance with $\mathrm{p}$ value $<0.001$.

Table:-Distribution of ADIPONECTIN, LEPTIN and CHEMERIN in two groups.

\begin{tabular}{|l|c|c|c|c|c|c|c|c|}
\hline & \multicolumn{5}{|c|}{ Case } & Control & & \\
\hline & Mean & Median & $\begin{array}{c}\text { Std. } \\
\text { Deviation }\end{array}$ & Mean & Median & $\begin{array}{c}\text { Std. } \\
\text { Deviation }\end{array}$ & $\mathrm{p}$ Value & Significance \\
\hline ADIPONECTIN & 3.61 & 3.40 & 2.16 & 8.31 & 8.60 & 3.26 & $<0.001$ & Significant \\
\hline LEPTIN (ng/ml) & 17.72 & 10.29 & 12.05 & 13.78 & 9.08 & 10.30 & 0.054 & $\begin{array}{l}\text { Not } \\
\text { Significant }\end{array}$ \\
\hline CHEMERIN & 171.60 & 179.00 & 44.77 & 96.64 & 92.00 & 23.46 & $<0.001$ & Significant \\
\hline
\end{tabular}

Table:-Distribution of parameters according to Obesity.

\begin{tabular}{|c|c|c|c|c|c|c|c|c|}
\hline \multicolumn{7}{|l|}{ OBESITY } \\
\hline & No & Median & $\begin{array}{c}\text { Std. } \\
\text { Deviation }\end{array}$ & Mean & Median & $\begin{array}{c}\text { Std. } \\
\text { Deviation }\end{array}$ & p Value & Significance \\
\hline & Mean & & & & \\
\hline CHOL & 164.28 & 169.00 & 26.07 & 242.56 & 242.00 & 41.41 & $<0.001$ & Significant \\
\hline HDL & 50.11 & 51.00 & 12.28 & 51.71 & 52.50 & 14.24 & 0.474 & Not Significant \\
\hline LDL & 88.51 & 96.00 & 28.34 & 152.05 & 147.50 & 37.09 & $<0.001$ & Significant \\
\hline VLDL & 25.63 & 25.00 & 8.69 & 38.60 & 38.00 & 12.28 & $<0.001$ & Significant \\
\hline TG & 135.72 & 132.00 & 38.31 & 225.37 & 218.50 & 39.77 & $<0.001$ & Significant \\
\hline FBG & 122.33 & 101.50 & 49.53 & 143.23 & 136.50 & 55.38 & 0.008 & Significant \\
\hline PPBG & 163.15 & 126.00 & 80.85 & 198.34 & 186.50 & 86.31 & 0.003 & Significant \\
\hline HBa1C & 6.95 & 6.10 & 2.18 & 7.77 & 7.80 & 2.19 & 0.012 & Significant \\
\hline HOMA IR & 4.80 & 3.52 & 3.61 & 6.24 & 6.63 & 3.34 & 0.026 & Significant \\
\hline ADIPONECTIN & 7.17 & 6.70 & 3.40 & 3.26 & 2.40 & 2.50 & $<0.001$ & Significant \\
\hline LEPTIN (ng/ml) & 8.75 & 8.36 & 1.75 & 31.33 & 31.46 & 7.50 & $<0.001$ & Significant \\
\hline CHEMERIN & 129.80 & 112.00 & 53.28 & 143.73 & 134.00 & 47.35 & 0.033 & Significant \\
\hline
\end{tabular}

Table:-Correlation of ADIPONECTIN, LEPTIN and CHEMERIN according to parameters.

\begin{tabular}{|c|c|c|c|c|c|}
\hline & & & ADIPONECTIN & $\begin{array}{l}\text { LEPTIN } \\
(\mathrm{ng} / \mathrm{ml})\end{array}$ & CHEMERIN \\
\hline \multirow[t]{13}{*}{ Spearman's rho } & \multirow[t]{2}{*}{ CHOL } & $\begin{array}{l}\text { Correlation } \\
\text { Coefficient }\end{array}$ & -0.453 & 0.907 & 0.143 \\
\hline & & p Value & $<0.001$ & $<0.001$ & 0.044 \\
\hline & \multirow[t]{2}{*}{ HDL } & $\begin{array}{l}\text { Correlation } \\
\text { Coefficient }\end{array}$ & -0.036 & -0.104 & 0.039 \\
\hline & & p Value & 0.617 & 0.142 & 0.585 \\
\hline & \multirow[t]{2}{*}{ LDL } & $\begin{array}{l}\text { Correlation } \\
\text { Coefficient }\end{array}$ & -0.391 & 0.853 & 0.081 \\
\hline & & p Value & $<0.001$ & $<0.001$ & 0.253 \\
\hline & \multirow[t]{2}{*}{ VLDL } & $\begin{array}{l}\text { Correlation } \\
\text { Coefficient }\end{array}$ & -0.317 & 0.579 & 0.103 \\
\hline & & p Value & $<0.001$ & $<0.001$ & 0.147 \\
\hline & \multirow[t]{2}{*}{ TG } & $\begin{array}{l}\text { Correlation } \\
\text { Coefficient }\end{array}$ & -0.490 & 0.756 & 0.209 \\
\hline & & $\mathrm{p}$ Value & $<0.001$ & $<0.001$ & 0.003 \\
\hline & \multirow[t]{2}{*}{ FBG } & $\begin{array}{l}\text { Correlation } \\
\text { Coefficient }\end{array}$ & -0.572 & 0.093 & 0.587 \\
\hline & & $\mathrm{p}$ Value & $<0.001$ & 0.191 & $<0.001$ \\
\hline & PPBG & Correlation & -0.577 & 0.139 & 0.610 \\
\hline
\end{tabular}




\begin{tabular}{|c|c|c|c|c|c|}
\hline & Coefficient & & & \\
\cline { 3 - 6 } & p Value & $<0.001$ & 0.050 & $<0.001$ \\
\cline { 2 - 6 } & \multirow{3}{*}{ HBa1C } & $\begin{array}{c}\text { Correlation } \\
\text { Coefficient }\end{array}$ & -0.575 & 0.085 & 0.642 \\
& p Value & $<0.001$ & 0.233 & $<0.001$ \\
\cline { 2 - 6 } & HOMA IR & $\begin{array}{c}\text { Correlation } \\
\text { Coefficient }\end{array}$ & -0.583 & 0.061 & 0.620 \\
\cline { 3 - 6 } & p Value & $<0.001$ & 0.390 & $<0.001$ \\
\cline { 3 - 6 } & \multirow{2}{*}{ BMI } & $\begin{array}{c}\text { Correlation } \\
\text { Coefficient }\end{array}$ & -0.468 & 0.962 & 0.112 \\
\cline { 3 - 6 } & p Value & $<0.001$ & $<0.001$ & 0.115 \\
\hline
\end{tabular}

\section{Conclusion:-}

The present findings shed light on the significant role of circulating adipokines in the patho-physiology of obesity and diabetes mellitus.

Low levels of adiponectin are associated with lipid abnormalities, insulin resistance and increased risk of diabetes. The causative role of adiponectin remains to be proven.

Adiponectin concentrations might also be used to decide on the aggressiveness of intervention and to monitor treatment. It have suggested that adiponectin levels may be used to monitor the efficacy of interventions in patients with diabetes. Change in adiponectin level reflects the effects of therapy.

Although these adipokines may be used as a biologic marker to assess risk and monitor treatment, estimations are seldom performed in clinical practice. The use of adiponectin, leptin and chemerin has so far been confined to clinical trials. Nevertheless the potential to use these hormones as biological risk markers certainly exists.

\section{References:-}

1. Joshi SR, Parikh RM India-diabetes capital of the world :now heading towards hypertension. J Assoc Physicians India. 2007;55:323-4.

2. Kumar A, Goel MK, Jain RB, Khanna P, Chaudhary V. India towards diabetes control: Key issues. Australas Med J. 2013;6(10):524-31.

3. Shimomura I, Funahashi T, Takahashi M, Maeda K, Kotani K, Nakamura T, et al. Enhanced expression of PAI1 in visceral fat: possible contributor to vascular disease in obesity. Nat Med 1996;2:800-2.

4. Spiegelman BM, Flier JS. Adipogenesis and obesity: rounding out the big picture Cell.1996;87:377-89.

5. Burtis A, Ashwood R, Bruns E, editors. Tietz textbook of clinical chemistry and molecular diagnostics. $4^{\text {th }}$ edition. New Delhi: Elsevier Inc.; 2006: 1024.

6. Wannamethee SG. Tchernova J. Whincup P. Lowe GDO. Kelley A. Rumley A. Wallace AM. Sattar N. Plasma leptin: Associations with metabolic, inflammatory and haemostatic risk factors for cardiovascular disease. Atherosclerosis. 2007;191:418-26

7. Kieffer TJ. Heller RS. Leech CA. Holz GG. Habener JF. Leptin suppression of insulin secretion by the activation of ATP-sensitive K+ channels in pancreatic beta-cells. Diabetes.1997;46:1087-93

8. Kulkarni RN. Wang ZL. Wang RM. Hurley JD. Smith DM. Ghatei MA. Withers DJ. Gardiner JV. Bailey CJ. Bloom SR. Leptin rapidly suppresses insulin release from insulinoma cells, rat and human islets and, in vivo, in mice. J Clin Invest. 1997;100:2729-36.

9. Steinberg GR, Parolin ML, Heigenhauser GJ, Dyck DJ. Leptin increases FA oxidation in lean but not obese human skeletal muscle: evidence of peripheral leptin resistance. Am J Physiol Endocrinol Metab. 2002;283:E187-E192.

10. Haffner SM, Stern MP, Miettinen H, Wei M, Gingerich RL. Leptin concentrations in diabetic and nondiabetic Mexican-Americans. Diabetes. 1996;45:822-4.

11. Sumner AE, Falkner B, Kushner H, Considine RV. Relationship of leptin concentration to gender, menopause, age, diabetes, and fat mass in African Americans. Obes Res.1998;6:128-33.

12. Maahs DM. Hamman RF. D'Agostino R., Jr Dolan LM. Imperatore G. Lawrence JM. Marcovina SM. MayerDavis EJ. Pihoker C. Dabelea D. The association between adiponectin/leptin ratio and diabetes type: the SEARCH for Diabetes in Youth Study. J Pediatr. 2009;155:133-5. 
13. Wannamethee SG. Lowe GD. Rumley A. Cherry L. Whincup PH. Sattar N. Adipokines and risk of type 2 diabetes in older men. Diabetes Care. 2007;30:1200-5.

14. Welsh P. Murray HM. Buckley BM. de Craen AJM. Ford I. Jukema JW. Macfarlane PW. Packard CJ. Stott DJ. Westendorp RGJ. Shepherd J. Sattar N. Leptin predicts diabetes but not cardiovascular disease: results from a large prospective study in an elderly population.Diabetes Care. 2009;32:308-10.

15. McNeely MJ. Boyko EJ. Weigle DS. Shofer JB. Chessler SD. Leonnetti DL. Fujimoto WY. Association between baseline plasma leptin levels and subsequent development of diabetes in Japanese Americans. Diabetes Care. 1999;22:65-70.

16. Soderberg S. Zimmet P. Tuomilehto J. Chitson P. Gareeboo H. Alberti KGMM. Shaw JE. Leptin predicts the development of diabetes in Mauritian men, but not women: a population-based study. Int $\mathrm{J}$ Obes (Lond) 2007;31:1126-33.

17. Schmidt MI. Duncan BB. Vigo A. Pnakow JS. Couper D. Ballantyne CM. Hoogeveen RC. Heiss G. for the ARIC Investigators. Leptin and incident type 2 diabetes: risk or protection? Diabetologia. 2006;49:2086-96.

18. Sun Q, van Dam RM. Meigs JB. Franco OH. Mantzoros CS. Hu FB. Leptin and soluble leptin receptor levels in plasma and risk of type 2 diabetes in U.S. women: A prospective study. Diabetes. 2010 Mar; 59(3):611-8.

19. Bozaoglu K, Bolto K, McMillan J, et al. Chemerin is a novel adipokine associated with obesity and metabolic syndrome. Endocrinology, 2007; 148, 4687-94.

20. Roh SG, Song SH, Choi KC, et al. Chemerin - a new adipokine that modulates adipogenesis via its own receptor. Biochemical and Biophysical Research Communications, 2007; 362, 1013-8.

21. Wittamer V, Bondue B, Guillabert A, et al. Neutrophilmediated maturation of chemerin: a link between innate and adaptive immunity. Journal of Immunology, 2005; 175, 487-93.

22. Wittamer V, Franssen JD, Vulcano M, et al. Specific recruitment of antigen-presenting cells by chemerin, a novel processed ligand from human inflammatory fluids. The Journal of Experimental Medicine, 2003;198, 977-85.

23. Zabel BA, Allen SJ, Kulig P, et al. Chemerin activation by serine proteases of the coagulation, fibrinolytic, and inflammatory cascades. The Journal of Biological Chemistry, 2005; 280, 34661-6.

24. Parolini S, Santoro A, Marcenaro E, et al. The role of chemerin in the colocalization of NK and dendritic cell subsets into inflamed tissues. Blood. 2007; 109, 3625-2.

25. Roh S,Song S, Choi K,et al. "Chemerin - a new adipokine that modulates adipogenesis via its own receptor," Biochemicaland Biophysical Research Communications.2007; 362(4 )1013-8.

26. Goralski KB, McCarthy TC, Hanniman EA ,et al. "Chemerin, a novel adipokine that regulates adipogenesis and adipocytemetabolism," Journal of Biological Chemistry.2007; 282(38) 28175-88,

27. Bozaoglu K, Segal D, Shields KA,et al "Chemerin is associated with metabolic syndrome phenotypes in a Mexican- American population,"The Journal of Clinical Endocrinology \&Metabolism. 2009; 94(8) 3085-8.

28. Looker HC, Krakoff J, Funahashi T, Matsuzawa Y, Tanaka S, Nelson RG, et al. The Journal of Clinical Endocrinology \& Metabolism. 2004;89:4010-17.

29. M. Abdelgadir, M. Elbagir, M. Eltom, C. Berne, B. Ahr[eacute].Reduced leptin concentrations in subjects with type 2 diabetes mellitus in Sudan. 2002 Mar;51(3):304-6.

30. Coimbra S, Proença JB, Santos-Silva A, Neuparth MJ. Adiponectin, Leptin, and Chemerin in Elderly Patients with Type 2 Diabetes Mellitus: A Close Linkage with Obesity and Length of the Disease. BioMed Research International. 2014;Article ID 701915:8 pages.

31. Abdullah SG, Mohammed AA. Mechanism linking diabetes mellitus and obesity. Dovepress. 2014 Dec;7:587591.

32. Staiger H, Tschritter O, Machann J, Thamer C.Relationship of serum adiponectin and leptin concentrations with body fat distribution in humans. Obes Res. 2003 Mar;11(3):368-72.

33. Phillips SA, Ciaraldi TP, Kong APS, Bandukwala R, Aroda V, Carter L, et al. Modulation of circulating and adipose tissue adiponectin levels by antidiabetic therapy. Diabetes. 2003;52:667-74.

34. Smith J, Al-Amri M, Sniderman A ,Katherine Cianflone. Leptin and adiponectin in relation to body fat percentage, waist to hip ratio and the apoB/apoA1 ratio in Asian Indian and Caucasianmen and women. Nutrition \& Metabolism. 2006; 3:18.

35. Pavani Bandaru. Association Between Plasma Leptin Levels and Diabetes Mellitus. METABOLIC SYNDROME AND RELATED DISORDERS. 2011;9(1).

36. Weigert J, Neumeier M, Wanninger J, Filarsky M, Bauer S, Wiest R, et al. Systemic chemerin is related to inflammation rather than obesity in type 2 diabetes. Clinical Endocrinology. 2010;72:342-8

37. Li Y, Shi B, Li S. Association between Serum Chemerin Concentrations and Clinical Indices in Obesity or Metabolic Syndrome: A Meta-Analysis. 2014 DEC 14. DOI: 10.1371/journal.pone.0113915. 